\title{
Cell wall proteome analysis of Mycobacterium smegmatis strain MC2 155
}

\author{
Zhiguo He and Jeroen De Buck*
}

\begin{abstract}
Background: The usually non-pathogenic soil bacterium Mycobacterium smegmatis is commonly used as a model mycobacterial organism because it is fast growing and shares many features with pathogenic mycobacteria. Proteomic studies of M. smegmatis can shed light on mechanisms of mycobacterial growth, complex lipid metabolism, interactions with the bacterial environment and provide a tractable system for antimycobacterial drug development. The cell wall proteins are particularly interesting in this respect. The aim of this study was to construct a reference protein map for these proteins in M. smegmatis.

Results: A proteomic analysis approach, based on one dimensional polyacrylamide gel electrophoresis and LC-MS/MS, was used to identify and characterize the cell wall associated proteins of M. smegmatis. An enzymatic cell surface shaving method was used to determine the surface-exposed proteins. As a result, a total of 390 cell wall proteins and 63 surface-exposed proteins were identified. Further analysis of the 390 cell wall proteins provided the theoretical molecular mass and p/ distributions and determined that 26 proteins are shared with the surface-exposed proteome. Detailed information about functional classification, signal peptides and number of transmembrane domains are given next to discussing the identified transcriptional regulators, transport proteins and the proteins involved in lipid metabolism and cell division.

Conclusion: In short, a comprehensive profile of the M. smegmatis cell wall subproteome is reported. The current research may help the identification of some valuable vaccine and drug target candidates and provide foundation for the future design of preventive, diagnostic, and therapeutic strategies against mycobacterial diseases.
\end{abstract}

\section{Background}

Although Mycobacterium smegmatis was originally isolated from humans, this fast-growing mycobacterium species is mostly nonpathogenic and has been used as a model to investigate mycobacterial physiology $[1,2]$. This fast-growing nonpathogenic bacterium is particularly useful in studying basic cellular processes of relevance to pathogenic mycobacteria, such as Mycobacterium tuberculosis, M. avium subsp. paratuberculosis and M. leprae, respectively the causative agent of tuberculosis, Johne's disease and leprosy. Although the genome sequencing of $M$. smegmatis is completed, much is unknown about the mechanisms controlling growth in mycobacterial species. As occurs with all free living bacteria, cells of M. smegmatis are surrounded by a cell wall responsible for providing

*Correspondence: jdebuck@ucalgary.ca

1 Department of Production Animal Health, Faculty of Veterinary Medicine, University of Calgary, 3330 Hospital Drive NW, Calgary, AB T2N 4N1, Canada Full list of author information is available at the end of the article their shape. The wall also provides protection to the cell to withstand the difference in osmotic pressure with the medium, and against other physical and chemical aggressions. Nevertheless, the cell wall must not be considered as a static structure; its chemical composition and the assembly of the different macromolecules that make it up are modified during cell growth and morphogenesis. A characteristic feature of mycobacteria is the thick, waxy cell wall, a highly impermeable outer surface, which enables mycobacteria to survive in extreme environmental conditions and the presence of antibiotics. The cell envelope structure of Mycobacteria is different from other gram positive bacteria, by the fact that it has two lipid layers, one being a regular inner membrane, the second being a layer mainly consisting of mycolic acids. This mycomembrane is very tightly connected to the peptidoglycan and arabinomannan inner layers of the cell wall. The surface is very complex, composed of proteins, sugars, and lipids that are in part conserved across the Myco- 
bacterial genus. While many of the cell wall proteins are burried inside the cell wall, some are surface exposed and likely play an even greater role in many vital processes such as cell-cell interactions, ion and nutrient transport and cell signaling, and participate in the key pathogenically relevant cellular mechanisms. Many proteins required for the pathogenicity of Mycobacteria are surface proteins that are involved in lipid metabolism and transport across the cell envelope [3,4]. Surface proteins are exposed to the external environment. As a result, these proteins are ideally positioned to protect the bacterium or to modify the host immune response to the bacillus. So research on the cell wall proteome of $M$. smegmatis provides promising candidates for vaccine and drug development against pathogenic Mycobacterium spp., especially since it turns out that bacterial cell envelope together with plasma membrane proteins constitute the majority of currently known drug targets $[5,6]$.

While other studies have used 2 dimensional liquid chromatography to increase the number of protein identifications in a complex mixture by tandem mass spectrometry $[7,8]$, we have chosen for a proteomic shotgun approach where SDS-PAGE precedes LC-MS/MS to resolve the M. smegmatis cell wall proteome. Other studies have previously used this approach to resolve mycobacterial membrane proteins [9-12]. The goal of this study was to improve the identification of mybacterial cell wall and cell wall-associated proteins in Mycobacteria by analyzing the model organism Mycobacterium smegmatis.

\section{Results \& discussion}

\section{High-throughput identification of cell wall proteins with} SDS-PAGE + LC-MS/MS

Traditionally, proteomic analyses of cell wall samples involve the resolution of proteins using 2-DE followed by the identification of resolved proteins by MS [13]. However, a big proportion of cell wall proteins are membrane bound, and it is generally agreed that membrane proteins are highly underrepresented in 2 dimensional electrophoresis (2-DE) [14]. In view of the poor performance of the 2-DE technique for membrane proteins and because the electrophoretic resolution of 2-DE by contaminating mycolates and other cell wall components [15], an alternative approach for the analysis of the cell wall proteome, shotgun LC-MS/MS method, was conducted. Cell wall proteins were first separated by SDS-PAGE according to their molecular weight followed by in-gel digested with trypsin into complex peptide mixture, and then the mixture was analyzed directly by LC-MS/MS. Subsequently, protein identifications were determined by database searching software [16]. Our experiments led to the identification of a much wider range of proteins in cell wall fraction than those identified using the conventional 2-
DE based method and can therefore be used as a comprehensive reference for Mycobacterium spp. cell wall proteomic studies. To avoid false-positive hits, we applied strict criteria for peptide and proteins identification. Additional file 1 shows the identified proteins in detail. In total, 390 unique proteins were identified, which included 79 proteins previously annotated as hypothetical or conserved hypothetical, which is the largest number of cell wall and cell wall-associated proteins for mycobacteria reported in one study.

Hydrophobicity analysis of the identified cell wall proteins Potential cell wall associated proteins with 1-15 TMHs (Transmembrane helix) were assigned using TMHMM 2.0 program against the Mycobacterial smegmatis MC2 155 protein sequence database (excluding the possible signal sequences). In our study, 64 proteins (16.41\%) were identified to have at least 1 transmembrane domain. The predicted TMH numbers of these proteins ranged from 1 to 15 , and 34 contained at least two TMHs. The profile of TMH in cell wall proteins of $M$. smegmatis is very similar to previous reports about TMH in M. tuberculosis cell wall proteome [17]. The distribution of these TMHs is shown in Figure 1. The grand average of hydropathy(GRAVY) value, which is used to evaluate the hydrophilicity and hydrophobicity of a protein along with its amino acid sequence[18], was minus 0.96 . There are 21 proteins with GRAVY scores $\geq 0.4$, which are so hydrophobic that they are susceptible to precipitation during isoelectric focusing and impossible to be detected by 2DE. Some important proteins with many TMHs were identified in our study, for example, integral membrane protein MviN and the sugar transport protein including sugar $\mathrm{ABC}$ transporter permease protein and sugar transport protein[19]. Apparently, our optimized methods

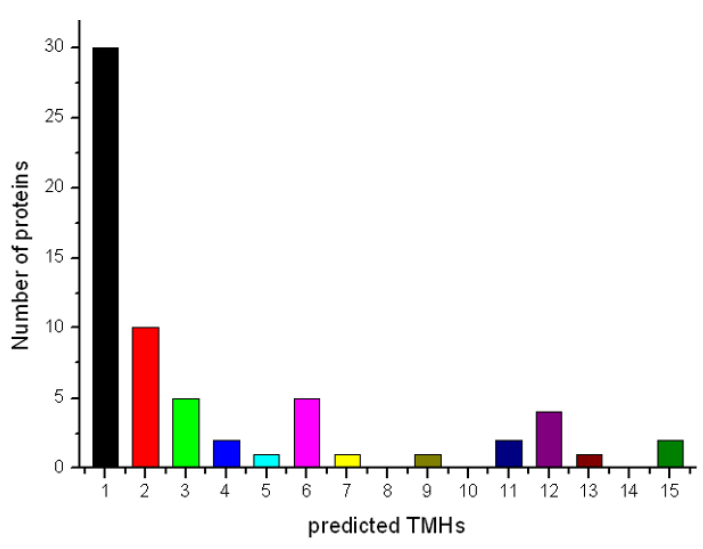

Figure 1 The distribution of the numbers of identified $M$. smegmatis cell wall proteins for each number of predicted TMHs as predicted by using the TMHMM2.0 program. 
provided a candidate platform that did not appear to be biased against proteins with high hydrophobicity or multiple TMHs.

\section{Molecular mass and pl distributions of the identified cell wall proteins}

The theoretical $M_{\mathrm{r}}$ distribution of the identified cell wall proteins ranged from $5.978 \mathrm{kDa}$ to $389.860 \mathrm{kDa}$. Moreover, proteins between $M_{\mathrm{r}} 10$ and $40 \mathrm{kDa}$ were in the majority, representing approximately $67.95 \%$ (265 out of 390) of all the identified cell wall proteins. Detailed distributions are shown in Figure 2. The theoretical $\mathrm{p} I$ scores of the identified cell wall proteins ranged from 4.16 to 11.56. Detailed distributions are shown in Figure 3. The theoretical $\mathrm{p} I$ and $M_{\mathrm{r}}$ distribution of the cell wall proteins is demonstrated in a Virtual 2D-gel in Figure 4A. Out of 390 proteins identified, it is obvious that the most proteins clustered around $\mathrm{p} I 4-7$, and $M_{\mathrm{r}} 10-40 \mathrm{kDa}$, which was similar with that of the total proteome (Figure 4B). There are 25 proteins with $\mathrm{p} I$ scores over 10 and 15 proteins with $M_{\mathrm{r}}$ over $100 \mathrm{kDa}$. Taking GRAVY value into account, there will be at least $61(21+25+15)$ proteins beyond the general 2-DE separation limits. Additionally, there are 49 proteins with predicted signal peptide in the 390 identified cell wall proteins (Figure 5A).

\section{Analysis of functional groups in identified cell wall protein}

Based on the Pasteur Institute functional classification tree http://www.ncbi.nlm.nih.gov/COG/, 390 identified proteins were distributed across twenty one of these functional groups (See table 1 for details). Most of the identified proteins were involved in general function prediction only (functional category $\mathrm{R}, 11.03 \%$ ), translation and transcription (16.15\%), amino acid transport and metabolism (7.17\%), energy production and conversion (5.90\%), posttranslational modification, protein turnover,

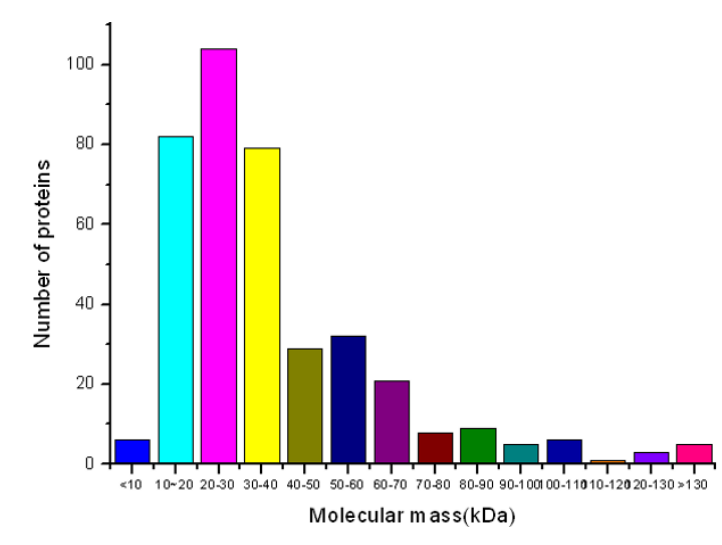

Figure 2 The distribution of molecular mass $\left(M_{r}\right)$ of the total identified $M$. smegmatis cell wall proteins.

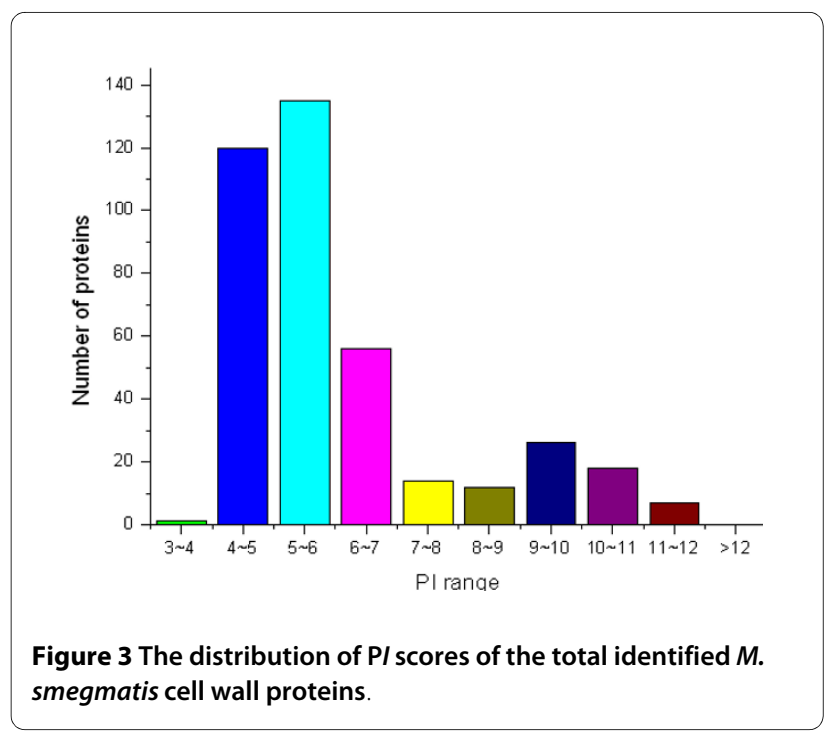

chaperones $(5.9 \%)$ and replication, recombination and repair (4.87\%) (Figure 6). Additionally, 4.62\% of the proteins could not be assigned functions in this manner, and $14.36 \%$ of the proteins had no related COG. $51.02 \%$ of proteins were involved in the six major functional categories above. Many unexpected proteins such as the ribosomal proteins were found to be cell wall associated, which were also found in cell wall by previous research $[17,20]$. It is probably these proteins interact tightly with the cell wall and join in cell envelop processes and would be potential significance in vaccine studies. Overlap between cytosolic, membrane and cell wall proteins in large scale proteomic studies is not uncommon. Additional studies are necessary to investigate the proteins with multiple cellular locations. The identification of heat-shock proteins in the cell surface exposed fraction might to some extent be due to the strong affinity of these proteins to cell wall proteins. Contact between cytoplasmic and cell surface exposed proteins can not be avoided during the extraction immediately for a brief moment after lysis.

\section{Surface exposed proteins}

Bacterial surface proteins play a fundamental role in the interaction between the bacterial cell and its environment [21-23]. They are involved in adhesion to and invasion of host cells, in sensing the chemical and physical conditions of the external milieu and sending appropriate signals to the cytoplasmic compartment, in mounting defenses against host responses and in toxicity. Therefore, surface exposed proteins are potential targets of drugs aimed at preventing bacterial infections and diseases [24]. Here, to identify the surface-exposed proteins of the M. smegmatis, exponentially growing bacteria were collected and treated with trypsin to shave the bacterial surface of exposed protein domains. In previous studies, 


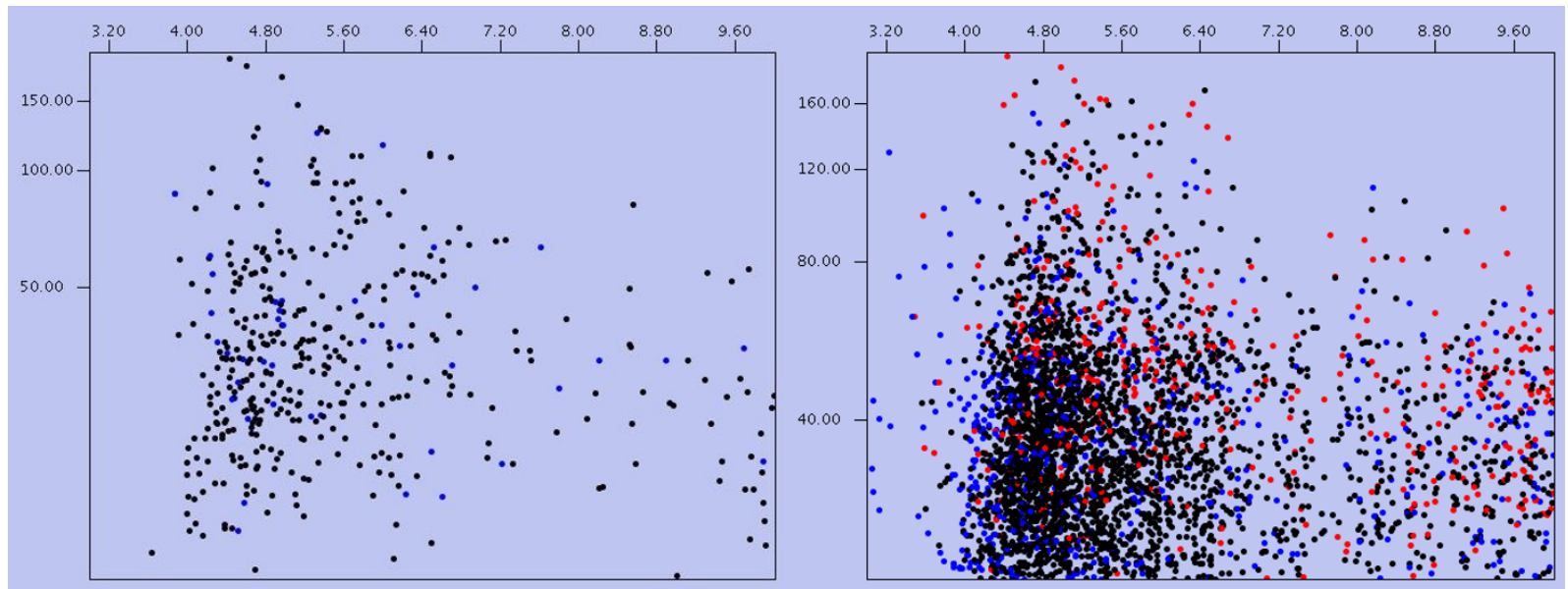

Figure 4 Virtual 2D-gel of $\boldsymbol{M}$. smegmatis CS2 155. (A) M. smegmatis cell wall proteome; (B) M. smegmatis total proteome.

this 'shaving' proteins technique has resulted in the identification of many surface exposed proteins $[20,25]$. The integrity of the cells after trypsin treatment was confirmed by viable counts, results of which confirmed the integrity of the cells (as seen in Additional file 2). Peptides released into the supernatant were collected to be fully digested with trypsin for 12 14 h, then concentrated and analyzed by LC-MS/MS. A total of 63 cell surface exposed proteins were successfully identified (as seen in table sup2). The predicted TMH numbers of these proteins ranged from 1 to 3 , and $14 \%$ of which contained at least two TMHs. The distribution of these TMHs is listed in Figure 7.55\% of the identified proteins have signal peptides (Figure 5B). As seen from Figure 8 that, 26 proteins of 63 found surface-exposed proteins overlapped with the cell wall proteins, which include 11 ribosomal proteins, acyl carrier protein, anion-transporting ATPase, chain A Main Porin, chaperonin GroEL, D-3-phosphoglycerate dehydrogenase, dihydrolipoamide acetyltransferase, DivIVA protein, DNA-directed RNA polymerase subunit beta, elongation factor Tu, enoyl-CoA hydratase, extracellular solute-binding protein family protein 5 , glycerol kinase, polyketide synthase, transcription termination

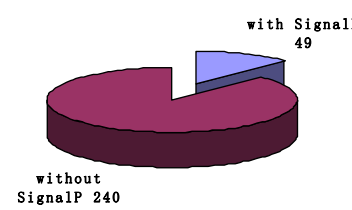

(A)

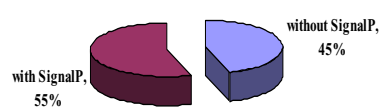

(B)
Figure 5 The distribution of proteins with SignalP in (A) M. smegmatis cell wall proteome; (B) M. smegmatis cell surface-exposed proteome. factor Rho and trigger factor. The control sample had no protein identified. The discrepancy between the identified surface exposed proteins and the complete cell wall proteome is likely due to the loose association of these proteins with the cell wall which make them prone to detachment. Indeed, some surface proteins are assumed to be attached to the cell wall in a non-covalent way and have been reported to be lost during mild standard manipulations [26,27]. EF-Tu(elongation factor thermo unstable) was identified as a cell wall related protein in this study, which was also been found as cell wall protein in other studies [28]. Translation elongation factors are responsible for two main processes during protein synthesis on the ribosome [29]. EF-Tu is responsible for the selection and binding of the cognate aminoacyl-tRNA to the A-site (acceptor site) of the ribosome. Till now, it is still unclear how proteins such as GroEL, divIVA and elongation factor TU belonging to the unexpected proteins within the M. smegmatis cell wall and cell surface exposed proteome leave the bacterial cell, are retained on the cell surface and whether they have an additional function when associated with the cell wall different from their known function inside the bacterial cell.

\section{Cell division}

The proteins related to cell division, divIVA, ftsK, ftsE, $\mathrm{ftsX}$, ftsH and ftsY, were identified as cell wall related proteins in this study. The divIVA gene, which for the most part is confined to gram-positive bacteria, was first identified in Bacillus subtilis. Cells with a mutation in this gene have a reduced septation frequency and undergo aberrant polar division, leading to the formation of anucleate minicells [30-32]. The divIVA gene codes for a protein that has been implicated in selection of septum positioning at midcell in vegetative division of $B$. subtilis, 
Table 1: Functional classification of the identified MC2 155 cell wall proteins

\begin{tabular}{|c|c|c|}
\hline Code & Description & Number \\
\hline $\mathbf{v}$ & Defense mechanisms & 1 \\
\hline $\mathbf{U}$ & Intracellular trafficking and secretion & 4 \\
\hline $\mathbf{T}$ & Signal transduction mechanisms & 16 \\
\hline $\mathbf{S}$ & Function unknown & 18 \\
\hline $\mathbf{R}$ & General function prediction only & 43 \\
\hline $\mathbf{Q}$ & $\begin{array}{l}\text { Secondary metabolites biosynthesis, } \\
\text { transport and catabolism }\end{array}$ & 12 \\
\hline $\mathbf{P}$ & Inorganic ion transport and metabolism & 13 \\
\hline 0 & $\begin{array}{l}\text { Posttranslational modification, protein } \\
\text { turnover, chaperones }\end{array}$ & 23 \\
\hline M & Cell wall/membrane biogenesis & 6 \\
\hline $\mathbf{L}$ & Replication, recombination and repair & 19 \\
\hline $\mathbf{K}$ & Transcription & 27 \\
\hline J & Translation & 36 \\
\hline $\mathbf{I}$ & Lipid transport and metabolism & 19 \\
\hline $\mathbf{H}$ & Coenzyme transport and metabolism & 16 \\
\hline G & Carbohydrate transport and metabolism & 18 \\
\hline $\mathbf{F}$ & Nucleotide transport and metabolism & 3 \\
\hline $\mathbf{E}$ & Amino acid transport and metabolism & 28 \\
\hline D & Cell cycle control, mitosis and meiosis & 7 \\
\hline C & Energy production and conversion & 23 \\
\hline A & RNA processing and modification & 1 \\
\hline- & Not in COGs & 56 \\
\hline
\end{tabular}

where it has been proposed to play a role similar to that of the $E$. coli MinE topological specificity component of the MinCDE division site selection system [33,34]. A divIVA gene is also present in Streptomyces coelicolor [35] and in other actinomycetes, like Mycobacterium tuberculosis, where Wag31 (antigen 84), a protein proposed to be involved in cell shape maintenance [36]. While many gram-positive bacteria may contain divIVA gene but lack minE and even the full minCDE system, many gram-negative bacteria have minE but no divIV.

FtsE, in association with the integral membrane protein FtsX, is involved in the assembly of potassium ion transport proteins, both of which being relevant to the tubercle bacillus. Recently FtsE and FtsX have been found to localize to the septal ring in E. coli, with the localization requiring the cell division proteins FtsZ, FtsA, and ZipA but not FtsK, FtsQ, FtsL, and FtsI proteins [37], suggestive of a role for FtsEX in cell division. Thus, since FtsE of the FtsEX complex shares sequence conservation with $\mathrm{ABC}$ type transporter proteins, the complex could be involved in the transport or translocation processes involving drugs, ions, solutes, proteins, peptides or polysaccharides in relation to drug resistance, salt tolerance, cell division or membrane protein insertion.

\section{Transcriptional regulators}

In total, There are 15 transcriptional regulators identified as cell wall related proteins in this work, among which include two ArsR-family proteins, three TetR family proteins and two two-component transcriptional regulatory proteins (detailed information given in Additional file 3). Two-component systems are major elements in bacterial adaptation to environmental changes. These systems are implicated in a large variety of adaptive responses, such as quorum sensing, chemotaxis and metabolic changes. In many pathogenic bacteria, two-component systems are central regulatory elements for the production of virulence factors $[38,39]$. In this study two two-component transcriptional regulatory proteins, PrrA and DevR were identified in the cell wall proportion. The prrA gene, encoding the regulator of the two-component system PrrA-PrrB, has been shown to be induced upon macrophage phagocytosis and to be transiently required for the early stages of macrophage infection for M. tuberculosis[40]. Adaptation to oxygen limitation is likely to consti- 


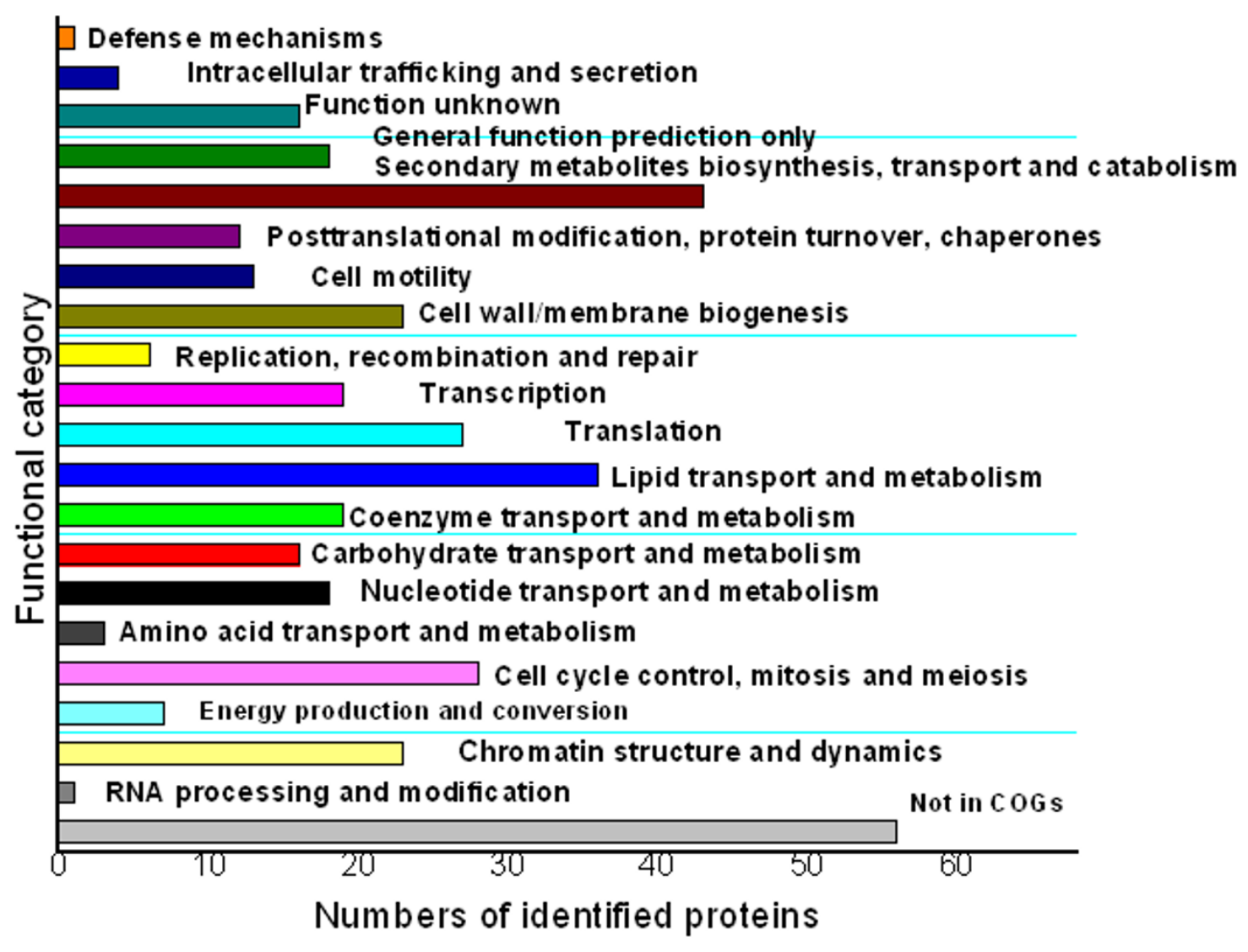

Figure 6 Functional classification of the identified $M$. smegmatis cell wall proteome.

tute a key step in mycobacterial persistence and dormancy and could well be mediated by a two-component system and it is suggested that DevR-DevS might serve as a regulatory link between hypoxia and establishment and/or maintenance of the appropriate response [41].

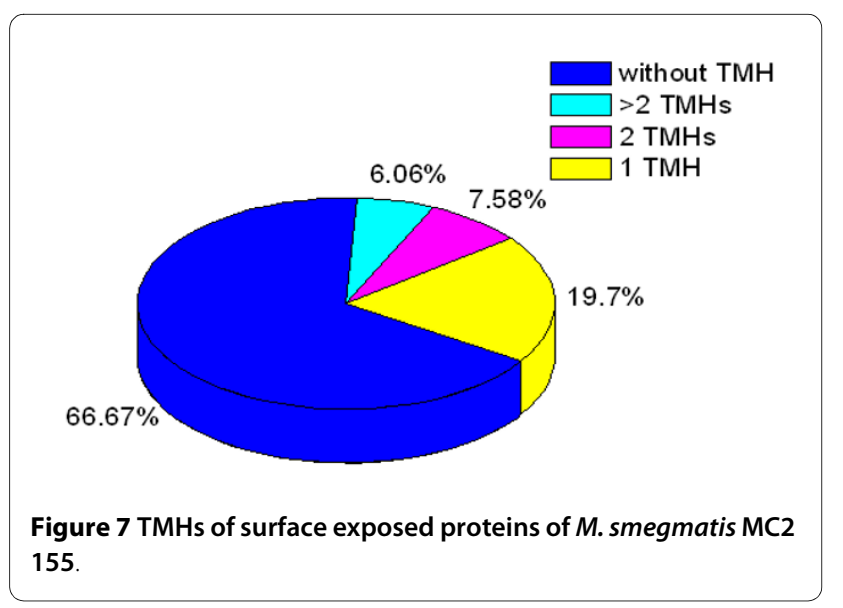

Lipid metabolism

The fatty acid components are the most energetically expensive molecules to produce, and thus the regulation of fatty acid production is very tightly controlled to match the growth rate of cells [42]. In this study, proteins related to lipid metabolism, cyclopropane-fatty-acyl-phospholipid synthase 1 , fatty acid desaturase, fatty acid synthase,

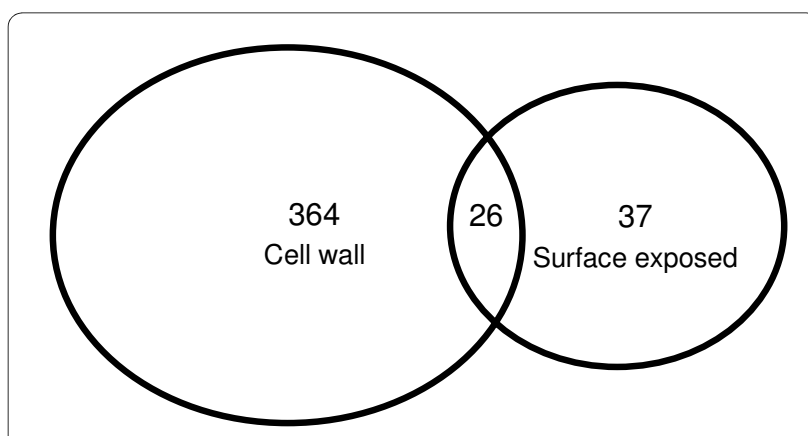

Figure 8 Venn diagram showing the overlap between cell wall \& cell surface exposed proteins 
methoxy mycolic acid synthase 1 , rhamnolipids biosynthesis 3-oxoacyl-[acyl-carrier-protein] reductase were identified in the cell wall proportion, among which fatty acid synthase and mycolic acid synthase (umaA) play important roles in mycolic acids metabolism. Mycolic acids are important and characteristic constituents of the mycobacterial cell wall. Changes in the structure or composition of mycolic acids have been associated with modification of cell wall permeability and attenuation of pathogenic Mycobacterial strains [43]. Many proteins like fatty acid synthase ACP, related to mycolic acids synthesis and elongation, are considered cell envelope-bound, which was confirmed in this study [44].

\section{Transport proteins}

A cell must selectively translocate molecules across its cell envelop to ensure that the chemical composition of its cytoplasm remains distinct from the surrounding medium [45]. The most important proteins for this purpose are the $\mathrm{ABC}$ transporters that actively transport chemically diverse sustrates across the cell wall [46]. The chemical nature of the substrates handled by $\mathrm{ABC}$ transporters is extremely diverse from inorganic ions to sugars and large polypeptides; yet $\mathrm{ABC}$ transporters are highly conserved. Overexpression of certain $\mathrm{ABC}$ transporters is the most frequent cause of resistance to cytotoxic agents including antibiotics, antifungals, herbicides, and anticancer drugs. It is well known that $\mathrm{ABC}$ transporters are modular and consist of proteins forming a channel, ATPase components and extracellular-binding proteins where some of these components can be fused together or not [47]. In this study, $28 \mathrm{ABC}$ transporters were identified. Out of these transporters, there were transmembrane proteins with one or six TMHs, and two have signal peptide. These proteins included 12 ATPase components which are predicted to be associated to transmembrane permease of ABC (ATP Binding Cassette) [48,49]. As found by Titgemeyer F. et al, there are 28 putative carbohydrate transporters in M. smegmatis and the majority of sugar transport systems (19/28) belong to the ATP-binding cassette $(A B C)$ transporter family [19]. In this study, 10 sugar transport proteins were found in cell wall fraction, and five of which are $A B C$ transporters [19]. Among the $A B C$ transporters identified, ATP binding protein of $A B C$ transporter and $A B C$ transporter periplasmic-binding protein $\mathrm{YtfQ}$, branched-chain amino acid $\mathrm{ABC}$ transporter substrate-binding protein, branched-chain amino acid $A B C$ transporter ATP-binding protein are in the same operon respectively.

\section{Conclusions}

We have obtained a comprehensive picture of the $M$. smegmatis cell wall protein repertoire, with an additional insight in the portion of these proteins that are cell surface exposed. With 390 distinct proteins identified, this study represents the first proteomic analysis of cell wall proteins of M. smegmatis MC2 155. It also represents the largest number of cell wall and cell wall-associated proteins for mycobacteria reported in one study.

Many of the cell wall-associated proteins appeared to have multiple subcellular localizations. In fact, some proteins previously reported as located in the cytoplasmic compartment were also associated with the bacterial cell wall and cell surface. These proteins supposedly transit between the cytosol and the cell wall compartments, and consequently, their localization, rather than to be strictly compartmentalized, could also depend on physiological and/or environmental conditions. Moreover, their moonlighting role at different subcellular localizations remains to be elucidated in M. smegmatis.

\section{Methods}

\section{Bacterial strain and growth conditions}

M. smegmatis MC2 155 was grown in Luria Broth (Becton Dickinson, Mississauga, ON, Canada) medium at $37^{\circ} \mathrm{C}$ with constant agitation $(200 \mathrm{rpm})$ until mid-exponential growth phase. The culture was harvested by centrifugation for $10 \mathrm{~min}$ at $10000 \times \mathrm{g}$ at $4^{\circ} \mathrm{C}$ and washing three times with ice-cold phosphate buffered saline (PBS) (pH7.4). The pelleted cells were frozen at $-80^{\circ} \mathrm{C}$ until needed.

\section{Cell wall proteins preparation}

The extraction of cell wall proteins from M. smegmatis MC2 155 was carried out according to Sanjeev et al. with minor modification [50]. Cells from a $1 \mathrm{~L}$ culture were harvested at $4400 \times \mathrm{g}$ and washed with $\mathrm{NaCl}$ solution $(0.16 \mathrm{M})$. The weight of wet cells was determined and for each gram of bacteria one ml lysis buffer $(0.05 \mathrm{M}$ potassium phosphate, $0.022 \%(\mathrm{v} / \mathrm{v}) \beta$-mercaptoethanol, $\mathrm{pH}$ 6.5) was added. Lysozyme (Roche, Mississauga, ON, Canada) was added to the cells to a final concentration of $2.4 \mathrm{mg} /$ $\mathrm{ml}$. The cells were then incubated at $37^{\circ} \mathrm{C}$ for $2 \mathrm{~h}$. Subsequently, cells (maintained in screw cap Eppendorf tubes) were disrupted with a bead beater (Biospec products, USA) for 4-6 times (1.5 min each time, ice cool down at intervals). The lysates were subjected to a low speed centrifugation at $600 \times \mathrm{g}$ to remove unbroken cells. Centrifugation was repeated 3 to 5 times for $40 \mathrm{~min}$ at 22,000 $\times \mathrm{g}$ to pellet the cell walls. All pellets were resuspended and pooled. A second cell lysis the same as before was performed on the pooled pellet. A single centrifugation at $22,000 \times$ g gave the pellet of cell wall fraction. The pellet was resuspended and centrifugated at $22,000 \times \mathrm{g}$, then stored frozen at $-80^{\circ} \mathrm{C}$.

\section{Bacterial surface digestion}

Procedure was carried out according to Guido Grandi et al [20] with some modifications. Bacteria were harvested from culture at an OD600 of 0.4 (exponential phase) by 
centrifugation at 3,500 $\times$ g for $10 \mathrm{~min}$ at $4^{\circ} \mathrm{C}$, and washed three times with PBS. Cells were resuspended in onehundredth volume of PBS containing 40\% sucrose (pH 7.4). Digestions were carried out with $20 \mathrm{mg}$ proteomic grade trypsin (Sigma-Aldrich, Oakville, ON, Canada) in the presence of $5 \mathrm{mM} \mathrm{DTT}$, for $30 \mathrm{~min}$ at $37^{\circ} \mathrm{C}$. A control experiment was carried out in parallel in which we incubated M. smegmatis cells in the "trypsin shaving" incubation buffer without trypsin for 2 hours. The digestion mixtures were centrifuged at $3,500 \times \mathrm{g}$ for $10 \mathrm{~min}$ at $4^{\circ} \mathrm{C}$, and the supernatants (Fresh trypsin was added) were incubated at $37^{\circ} \mathrm{C}$ for around $12 \sim 14 \mathrm{hrs}$ for full digestion after being filtered using $0.22 \mu \mathrm{m}$ pore-size filters (Millipore, Etobicoke, ON, Canada). Protease reactions were stopped with formic acid at $0.1 \%$ final concentration. Peptide fractions were concentrated with a Speed-vac centrifuge (Savant), and kept at $-20^{\circ} \mathrm{C}$ until further analysis.

\section{Sample digestion}

Protein sample was separated by $12.5 \%$ sodium dodecyl sulfate polyacrylamide gel (SDS-PAGE), run for $1 \mathrm{~h}$ at 30 $\mathrm{W}$, then for $4.5 \mathrm{~h}$ at $180 \mathrm{~W}$. The gels were Coomassie Brilliant Blue stained and the lane corresponding to the cell wall proteins was cut into 6 equal pieces. The gel pieces were individually in-gel digested as described previously with some modifications [50]. Briefly, after in-gel digestion using trypsin, the digested solution was transferred into a clean $0.6 \mathrm{ml}$ tube. Fifty microliters of $50 \%$ acetonitrile $(\mathrm{ACN}) / 5 \%$ formic acid (FA) was added to the gel pieces and sonicated for $30 \mathrm{~min}$. This extraction procedure was repeated three times, and a total of $150 \mu \mathrm{l}$ of extracts was collected. All extracts were pooled and concentrated to less than $10 \mu \mathrm{l}$ using an SPD 2010 SpeedVac system (Thermo Electron, Waltham, MA). Thereafter, the sample was diluted with $0.1 \%$ FA in HPLC water to $100 \mu \mathrm{L}$ for direct LC-MS/MS analysis or reconstituted with trifluoroacetic acid (TFA) to a final concentration of $0.1 \%$ and subjected to sample cleanup steps using C18 ZipTips (Millipore) prior to LC-MS/MS analysis. The C18 ZipTips were conditioned with $100 \%$ ACN and then equilibrated three times with $0.1 \%$ TFA. The peptides were bound to the ZipTip pipet tip by aspirating and dispensing the sample for at least 15 cycles, washed with $0.1 \%$ TFA, and eluted by $20 \mu \mathrm{L}$ of elution buffer $(75 \%$ ACN, $0.1 \%$ TFA).

\section{Protein identification by LC-MS/MS}

Digests were analyzed using an integrated Agilent 1100 LC-ion-Trap-XCT-Ultra system fitted with an Agilent ChipCube source sprayer. Injected samples were first trapped and desalted on a Zorbax 300 SB-C18 Precolumn ( $5 \mu \mathrm{m}, 5 \times 300-\mu \mathrm{m}$ inside diameter; Agilent) for $5 \mathrm{~min}$ with $0.2 \%$ formic acid delivered by the auxiliary pump at
$0.3 \mu \mathrm{l} / \mathrm{min}$. The peptides were then reverse eluted from the trapping column and separated on an analytical Zorbax $15 \mathrm{~cm}$-long 300SB-C18 HPLC-Chip $0.3 \mu \mathrm{l} / \mathrm{min}$. Peptides were eluted with a $5-45 \%$ acetonitrile gradient in $0.2 \%$ formic acid over a $50 \mathrm{~min}$ interval. Data-dependent acquisition of collision-induced dissociation MS/MS was utilized, and parent ion scans were run over the mass range $\mathrm{m} / \mathrm{z} 400-2,000$ at 8,100. For analysis of LC-MS/MS data, Mascot searches used the following parameters: 1.4 Da MS error, $0.8 \mathrm{Da}$ MS/MS error, 1 potential missed cleavage, and variable oxidation (Methionine) [51].

\section{Protein identification}

Data files from the chromatography runs were batch searched against the $M$. smegmatis proteome database using the SEQUEST algorithm16 contained within Bioworks v3.1 software [52]. The criteria used for protein identification were as follows. For positive identification of any individual protein, a minimum of two peptides was required. The minimum cross-correlation coefficients (Xcorr) of 1.9, 2.2, and 3.75 for singly, doubly, and triply charged precursor ions respectively and a minimum ?Cn of 0.1 were both required for individual peptides. For false positive analysis, a decoy search was performed automatically by choosing the Decoy checkbox on the search form.

\section{Physicochemical characteristics and subcellular localization of the identified proteins}

The full set of M. smegmatis MC2 155 ORFs was downloaded from the NCBI databases, including 6938 ORFs. The codon adaptation indices (CAI) and hydrophilicity of the proteins were calculated with the standalone version of program CodonW (John Peden, http://bioweb.pasteur.fr/seqanal/interfaces/codonw.html). The hydrophilicity was given as a GRAVY (Grand Average of Hydrophobicity) score [53], which is calculated as the sum of hydropathy values of all the amino acids, divided by the number of residues in the sequence. The TMHMM 2.0 program, based on a hidden Markov model http://www.cbs.dtu.dk/services/TMHMM/, was used to predict protein transmembrane topology [54]. The protein functional family was categorized according to the COG annotation terms http://www.ncbi.nlm.nih.gov/ COG/[55]. The virtual 2DE was produced according to Hiller et al. http://www.jvirgel.de/index.html[56].

\section{Additional material}

Additional file 1 Cell wall proteins list. A summarization of all the identified cell wall proteins of Mycobacterium smegmatis strain MC2 155.

Additional file $\mathbf{2}$ Bacterial viable test. A description of bacterial viable test comparison between cells pretreated with trypsin and control. 
Additional file 3 Cell surface-exposed proteins list. A summarization of all the identified cell surface proteins of Mycobacterium smegmatis strain MC2 155

\section{Authors' contributions}

ZGH carried out the proteomics study, analyzed the data and drafted the manuscript. JDB conceived of the study, and participated in its design and coordination. All authors have read and approved the final manuscript.

\section{Acknowledgements}

This work was financially supported by a grant of the Crohn's and Colitis Foundation of Canada.

\section{Author Details}

Department of Production Animal Health, Faculty of Veterinary Medicine, University of Calgary, 3330 Hospital Drive NW, Calgary, AB T2N 4N1, Canada

Received: 8 March 2009 Accepted: 22 April 2010

Published: 22 April 2010

\section{References}

1. Alvarez E, Tavel E: Recherches sur le bacille de Lustgarden. Arch Physiol Norm Pathol 1885, 6:303-321.

2. Provvedi R, Kocíncová D, Donà V, Euphrasie D, Daffé M, Etienne G, Manganelli R, Reyrat JM: SigF controls carotenoid pigment production and affects transformation efficiency and hydrogen peroxide sensitivity in Mycobacterium smegmatis. J Bacterio/ 2008, 190(23):7859-63.

3. Camacho LR, Ensergueix D, Perez E, Gicquel B: Guilhot Cldentification of a virulence gene cluster of Mycobacterium tuberculosis by signaturetagged transposon mutagenesis. Mol Microbiol 1999, 34(2):257-67.

4. Daffé M, Etienne G: The capsule of Mycobacteriumtuberculosis and its implications for pathogenicity. TuberLung Dis 1999, 79(3):153-69.

5. Hopkins AL, Groom CR: The druggable genome. Nature Reviews Drug Discovery 2002, 1:727-730

6. Rabilloud T: Membrane proteins ride shotgun. Nat Biotechnol 2003, 21:508-510

7. Washburn MP, Wolters D, Yates JR III: Large-scaleanalysis of the yeast proteome by multidimensional protein identification technology. Nat Biotechnol 2001, 19:242-247.

8. Wang R, Prince JT, Marcotte EM: Mass spectrometry of the M. smegmatis proteome: protein expression levels correlate with function, operons, and codon bias. Genome Res 2005, 15:1118-1126.

9. Gu S, Chen J, Dobos KM, Bradbury EM, Belisle JT, Chen X: Comprehensive proteomic profiling of the membrane constituents of a Mycobacterium tuberculosis strain. Mol Cell Proteomics 2003, 2:1284-1296.

10. Xiong Y, Chalmers MJ, Gao FP, Cross TA, Marshall AG: Identification of Mycobacterium tuberculosis H37Rv integral membrane proteins by one-dimensional gel electrophoresis and liquid chromatography electrospray ionization tandem mass spectrometry. J Proteome Res 2005, 4:855-861.

11. Mattow J, Siejak F, Hagens K, Schmidt F, Koehler C, Treumann A, Schaible UE, Kaufmann SHE: An improved strategy for selective and efficient enrichment of integral plasma membrane proteins of mycobacteria. Proteomics 2007, 7:1687-1701.

12. Malen H, Berven FS, Softeland T, Arntzen MO, D'Santos CS, De Souza GA Wiker HG: Membrane and membrane-associated proteins in Triton-114 extracts of Mycobacterium bovis BCG identified using a combination of gel-based and gel-free fractionation strategies. Proteomics 2008 , 8:1859-1870.

13. Santoni $\mathrm{V}$, Molloy M, Rabilloud T: Membrane proteins and proteomics: Un amour impossible? Electrophoresis 2000, 21:1054-1070.

14. Schluesener D, Fischer F, Kruip J, Rögner M, Poetsch A: Mapping the membrane proteome of Corynebacterium glutamicum. Proteomic 2005, 5:1317-1330.

15. Egan S, Lanigan M, Shiell B, Beddome G, Stewart D, Vaughan J, Michalski WP: The recovery of Mycobacterium avium subspecies paratuberculosis from the intestine of infected ruminants for proteomic evaluation. J Microbiol Methods 2008, 75:29-39.

16. Wu CC, Yates JR III: The application of mass spectrometry to membrane proteomics. Nat Biotechnol 2003, 21:262-267.
17. Mawuenyega KG, Forst CV, Dobos KM, Belisle JT, Chen J, Bradbury EM, Bradbury ARM, Chen X: Mycobacteriumtuberculosis functional network analysis by global subcellular protein profiling. Mol Biol Cell 2005, 16:396-404.

18. Zheng J, Wei C, Leng W, Dong J, Li R, Li W, Wang J, Zhang Z, Jin Q: Membrane subproteomic analysis of Mycobacterium bovis bacillus Calmette-Guérin. Proteomics 2007, 7(21):3919-31.

19. Titgemeyer F, Amon J, Parche S, Mahfoud M, Bail J, Schlicht M, Rehm N, Hillmann D, Stephan J, Walter B, Burkovski A, Niederweis M: A genomic view of sugar transport in Mycobacterium smegmatis and Mycobacterium tuberculosis. J Bacterio/ 2007, 189(16):5903-15.

20. Rodríguez-Ortega Manuel J, Norais Nathalie, Bensi Giuliano, Liberatori Sabrina, Capo Sabrina, Mora Marirosa, Scarselli Maria, Doro Francesco, Ferrari Germano, Garaguso Ignazio, Maggi Tiziana, Neumann Anita, Covre Alessia, Telford John L, Grandi Guido: Characterization and identification of vaccine candidate proteins through analysis of the group $A$ Streptococcus surface proteome. Nat Biotechnol 2006, 24(2):191-197.

21. Lindahl G, Stalhammar-Carlemalm M, Areschoug T: Surface proteins of Streptococcus agalactiae and related proteins in other bacterial pathogens. Clin Microbiol Rev 2005, 18:102-127.

22. Lin J, Huang S, Zhang Q: Outer membrane proteins: keyplayers for bacterial adaptation in host niches. Microbes Infect 2002, 4:325-331.

23. Niemann HH, Schubert WD, Heinz DW: Adhesins and invasins of pathogenic bacteria: a structural view. Microbes Infect 2004, 6:101-112.

24. Galperin MY, Koonin EV: Searching for drug targets in microbial genomes. Curr Opin Biotechnol 1999, 10:571-578

25. Newton V, McKenna SL, De Buck J: Presence of PPE proteins in Mycobacterium avium subsp.paratuberculosis isolates and their immunogenicity in cattle. Vet Microbiol 2009, 135:394-400.

26. Kocincova D, Sonden B, Mendonca-Lima L, Gicquel B, Reyrat JM: The Erp protein is anchored at the surface by a carboxy-terminal hydrophobic domain and is important for cell-wall structure in Mycobacterium smegmatis. Fems Microbiology Letters 2004, 231:191-196.

27. Lichtinger T, Burkovski A, Niederweis M, Kramer R, Benz R: Biochemical and biophysical characterization of the cell wall porin of Corynebacterium glutamicum : The channel is formed by a low molecular mass polypeptide. Biochemistry 1998, 37:15024-15032.

28. Nilsson J, Nissen P: Elongation factors on the ribosome. Curr Opin Struct Biol 2005, 15:349-54.

29. Vicente M, García-Ovalle M: Making a point: the role of DivIVA in streptococcal polar anatomy. J Bacteriol 2007, 189(4):1185-8

30. Mendelson $\mathrm{NH}$ : Cell division suppression in the Bacillus subtilis divIC-A1 minicell-producing mutant. J Bacterio/ 1975, 121:1166-1172.

31. Reeve JN, Mendelson NH, Coyne SI, Hallock LL, Cole RM: Minicells of Bacillus subtilis. J Bacteriol 1973, 114:860-873.

32. Edwards DH, Errington J: The Bacillus subtilis DivIVA protein targets to the division septum and controls the site specificity of cell division. Mol Microbiol 1997, 24:905-915.

33. Vicente $M$, Löwe J, helix Ring: sphere and cylinder: the basic geometry of prokaryotic cell division. EMBO Rep 2003, 4:655-660

34. Flärdh K: Essential role of DivIVA in polar growth and morphogenesis in Streptomyces coelicolor A3(2). Mol Microbiol 2003, 49:1523-1536.

35. Hermans PW, Abebe F, Kuteyi VI, Kolk AH, Thole JE, Harboe M: Molecular and immunological characterization of the highly conserved antigen 84 from Mycobacterium tuberculosis and Mycobacterium leprae. Infect Immun 1995, 63:954-960.

36. Schmidt KL, Peterson ND, Kustusch RJ, Wissel MC, Graham B, Phillips GJ, Weiss DS: A predicted ABC transporter, FtsEX, is needed for cell division in Escherichia coli. J Bacteriol 2004, 186:785-793.

37. Hoch JA: Two-component and phosphorelay signal transduction. Curr Opin Microbiol 2000, 3:165-170.

38. Stock AM, Robinson VL, Goudreau PN: Two-component signaltransduction. Annu Rev Biochem 2000, 69:183-215.

39. Boon C, Li R, Qi R, Dick T: Proteins of Mycobacterium bovis BCG induced in the Wayne dormancy model. J Bacteriol 2001, 183:2672-2676.

40. Ewann F, Jackson M, Pethe K, Cooper A, Mielcarek N, Ensergueix D, Gicquel B, Locht C, Supply P: Transient requirement of the PrrA-PrrB two-component system for early intracellular multiplication of Mycobacterium tuberculosis. Infect Immun 2002, 70(5):2256-63.

41. Barboni E, Coade S, Fiori A: The binding of mycolic acids to galectin-3: a novel interaction between a host soluble lectin and trafficking mycobacterial lipids? FEBS Lett 2005, 579(30):6749-55. 
42. Ewann F, Jackson M, Pethe K, Cooper A, Mielcarek N, Ensergueix D, Gicquel B, Locht C, Supply P: Transient requirement of the PrrA-PrrB two-component system for early intracellular multiplication of Mycobacterium tuberculosis. Infect Immun 2002, 70(5):2256-63.

43. Choi KH, Kremer L, Besra GS, Rock CO: Identification and substrate specificity of beta -ketoacyl (acyl carrier protein) synthase III ( $\mathrm{mtFabH})$ from Mycobacterium tuberculosis. J Biol Chem 2000, 275(36):28201-7.

44. Higgins CF, Linton KJ: The xyz of ABC transporters. Science 2001, 293:1782-1784

45. Dawson RJP, Locher KP: Structure of a bacterial multidrug ABC transporter. Nature 2006, 443:180-185.

46. Davidson AL, Chen J: ATP-binding cassette transporters in bacteria. Annu Rev Biochem 2004, 73:241-268.

47. Otto M, Götz F: ABC transporters of staphylococci. Res Microbio/ 2001 152(3-4):351-6

48. Higgins $C F: A B C$ transporters: physiology, structure and mechanism-an overview. Res Microbiol 2001, 152(3-4):205-10.

49. Gumber S, Taylor DL, Whittington RJ: Protein extraction from Mycobacterium avium subsp. paratuberculosis: Comparison of methods for analysis by sodium dodecyl sulphate polyacrylamide gel electrophoresis, native PAGE and surface enhanced laser desorption/ ionization time of flight mass spectrometry. J Microbio/ Methods 2007, 68(1):115-27.

50. Shevchenko A, Tomas H, Havlis J, Olsen JV, Mann M: In-gel digestion for mass spectrometric characterization of proteins and proteomes. Nat Protoc 2006, 1(6):2856-60.

51. Barinov A, Loux V, Hammani A, Nicolas P, Langella P, Ehrlich D, Maguin E, Guchte M: Prediction of surface exposed proteins in Streptococcus pyogenes, with a potential application to other Gram-positive bacteria. Proteomics 2008, 9(1):61-73.

52. Wei C, Yang J, Zhu J, Zhang X, Leng W, Wang J, Xue Y, Sun L Li W, Wang J, Jin Q: Comprehensive proteomic analysis of Shigella flexneri 2a membrane proteins. J Proteome Res 2006, 5(8):1860-5.

53. Kyte J, Doolittle RF: A simple method for displaying the hydropathic character of a protein. J Mol Biol 1982, 157:105-132.

54. Krogh A, Larsson B, von Heijne G, Sonnhammer EL: Predicting transmembrane protein topology with a hiddenMarkov model: application to complete genomes. J Mol Bio 2001, 305:567-580.

55. Tatusov RL, Koonin EV, Lipman DJ: A genomic perspective on protein families. Science 1997, 278:631-637.

56. Hiller K, Schobert M, Hundertmark C, Jahn D, Münch R, VirGel J: calculation of virtual two-dimensional protein gels. Nucleic Acids Res 2003, 31:3862-3865.

doi: $10.1186 / 1471-2180-10-12$

Cite this article as: He and De Buck, Cell wall proteome analysis of Mycobacterium smegmatis strain MC2 155 BMC Microbiology 2010, 10:121

Submit your next manuscript to BioMed Central and take full advantage of:

- Convenient online submission

- Thorough peer review

- No space constraints or color figure charges

- Immediate publication on acceptance

- Inclusion in PubMed, CAS, Scopus and Google Scholar

- Research which is freely available for redistribution

Submit your manuscript at www.biomedcentral.com/submit
C Biomed Central 